\title{
Congenital Rubella Syndrome: An Overview of Clinical Presentations in Bangladeshi Children
}

\author{
Nure Ishrat Nazme1, Md. Mahbubul Hoque², Manzoor Hussain³
}

\begin{abstract}
Background: Congenital Rubella Syndrome (CRS) has long been characterized by the triad of deafness, cataract and cardiovascular malformations with or without mental retardation. Objective: This study was conducted to observe the clinical manifestations of CRS in children of Bangladesh. Materials and method: This cross sectional study was carried out in Dhaka Shishu (Children) Hospital, Dhaka, Bangladesh and National Institute of Cardiovascular Diseases (NICVD), Dhaka, Bangladesh. Total 40 cases of CRS were enrolled from indoor and outpatient departments of these two hospitals, who were diagnosed according to standard case definition. Serological test for rubella antibody, chest X-ray, colour Doppler echocardiography, visual examination and hearing assessment were done in relative specialised centres. Results: The mean $( \pm S D)$ age of the study subjects was 6.6( \pm 5.7$)$ months (range: 0-24 months). Among the subjects, 68\% were male and $32 \%$ were female. Serum for rubella specific antibody revealed positive IgG in $60 \%$ cases and IgM in 28\% cases. Neurological problem was the most frequently observed (90\%) systemic complication followed by visual problem (83\%), congenital hearing loss (80\%) and congenital heart disease (78\%). Cataract was the commonest (55\%) among visual problems and microcephaly (62\%) among neurological manifestations. Patent ductus arteriosus (PDA) was the most common (37.5\%) isolated structural cardiac defect. Maximum (62.5\%) children came from poor socioeconomic status. Maternal onset of infection was commonly detected in 1st trimester of pregnancy. Conclusion: Diagnosis of CRS and recognition of its versatile pattern of clinical presentation are crucial for better prognosis of the affected children.
\end{abstract}

Keywords: Congenital Rubella Syndrome; clinical presentation; ELISA.

$$
\text { Delta Med Col J. Jul 2014;2(2): } 42-47
$$

\section{Introduction}

Rubella virus is a member of the togavirus family which is transmitted by direct droplet contact from nasopharyngeal secretions, replicates in the lymphoid tissue of the upper respiratory tract, and spreads hematogenously. ${ }^{1}$ The virus can infect and replicate in the placenta of pregnant women. The most devastating consequences of rubella infection during pregnancy are abortion, stillbirth, and foetal malformation that arise from maternal infection during the first trimester of pregnancy. ${ }^{2}$

Before the introduction of rubella vaccine in 1969, the global incidence of Congenital Rubella Syndrome (CRS) ranged from 0.8-4/1000 live births during rubella epidemics to about 0.1-0.2/1000 live births during endemic periods. ${ }^{3}$ According to the World Health Organization (WHO), an estimated

1. Resident Medical Officer, Dhaka Shishu (Children) Hospital, Dhaka, Bangladesh.

2. Professor of Paediatrics, Bangladesh Institute of Child Health, Dhaka Shishu (Children) Hospital, Dhaka, Bangladesh.

3. Professor \& Head of Paediatric Cardiology, Bangladesh Institute of Child Health, Director, Dhaka Shishu (Children) Hospital, Dhaka, Bangladesh.

Correspondence: Dr. Nure Ishrat Nazme. e-mail: nazssmc@gmail.com 
100,000 infants are affected each year worldwide. 4 Rubella is often not notified, as many cases are not seen by a doctor or even not recognized by the patient; consequently, rubella outbreaks can occur without clinical recognition. Thus, the estimated incidence of CRS defects is likely less than the true incidence. 5 Annual number of reported rubella cases in Bangladesh was 13,464 in 2009 and 13,125 in 2010 and rubella attack rate among antenatal population in Bangladesh is 14.5 in 1000 during pregnancy. 6,7

The CRS consists of the classic triad of cataract, sensorineural hearing loss, and congnital heart disese (CHD). ${ }^{8}$ In embryo, the most rapid development of heart muscle occurs along with the development of the inner ear and lens. Therefore, damage to the ears and eyes is often accompanied by a variety of heart defects. 9 Other clinical features include transient bone lesions, jaundice, IUGR, meningoencephalitis, thrombocytopenic purpura, hepatoslenomegaly, haemolytic anaemia, mental retardation, insulin dependent diabetes (IDDM) and central nervous system (CNS) defects (microcephaly, psychomotor retardation). ${ }^{10}$

There is diverse form of clinical pattern of CRS and treatment modalities differ in each type of manifestations. Therefore, early recognition of CRS and identification of accurate structural as well as functional defects are crucial for paediatricians.

\section{Materials and method}

This cross sectional study was conducted from December 2011 through July 2012 in Dhaka Shishu (Children) Hospital, Dhaka, Bangladesh and National Institute of Cardiovascular Diseases (NICVD), Dhaka, Bangladesh. During this period total 4160 patients were registered and the enrolled patients (0-24 months of age) were selected from outpatient department and indoor admissions of the study hospitals after clinical diagnosis of CRS according to WHO case definition. ${ }^{11}$ The study was approved by the ethical review committee of Bangladesh Institute of Child Health, Dhaka Shishu (Children) Hospital, Dhaka, Bangladesh. With prior written consent from the parents, clinical history and relevant data were recorded. Venous blood was collected aseptically from the study subjects and sera were tested by ELISA using a commercial kit in order to determine the level of antibody. The tests were carried out according to the manufacturer's instructions. IgG antibodies were considered positive when the serum level reached at $10 \mathrm{U} / \mathrm{ml}$ and $\operatorname{IgM}$ at $2.5 \mathrm{U} / \mathrm{ml}$. Chest X-ray, colour Doppler echocardiography, visual examination and hearing assessment were done in relative specialized centres.

\section{Results}

Among the 4160 registered cases, 40 children were suspected as CRS cases according to the case definition and enrolled in the study. Serum antibody against rubella was advised for all the subjects. High IgG and IgM levels were found in 24(60\%) and $11(28 \%)$ cases respectively. Three (8\%) cases refused to do investigation. In $2(5 \%)$ cases result was equivocal for IgG (Fig 1).

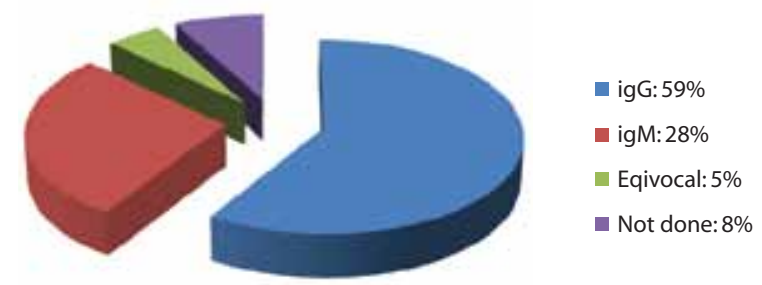

Fig 1: Distribution of CRS cases according to serum immunoglobulin level for rubella

Out of 40 children, 21(53\%) cases were between 0-6 months of age group. The mean $( \pm \mathrm{SD})$ age was 6.6 $( \pm 5.7)$ months; $27(68 \%)$ cases were male and $13(32 \%)$ were female.

Majority of the subjects (62\%) with CRS, came from poor family followed by upper middle class $(28 \%)$ and lower middle class family (10\%) respectively (Table I).

Table I: Distribution of the study patients according to socioeconomic status ${ }^{12}(\mathrm{~N}=\mathbf{4 0})$

\begin{tabular}{lcc}
\hline Socio Economic status & Frequency (N=40) & Percentage (\%) \\
\hline Poor & & \\
(Tk. up to 5,000 per month) & 25 & 62 \\
Lower middle class & 04 & 10 \\
(Tk.5,000 - up to 20,000 per month) & & \\
Upper middle class & 11 & 28 \\
(Tk. 20,000 - up to 60,000 per month) & & \\
\hline
\end{tabular}


Among the studied cases most of whom had major disabilities like cardiac defects, hearing impairment and visual problems, had history of maternal rubella infection in first trimester of pregnancy. No mother reported contracting rubella during their third trimester. For 6 cases ( 2 each for each disability), they could not mention the time of occurrence of infection (Table II).

Table II: Distribution of CRS related disabilities according to onset of infection during pregnancy

\begin{tabular}{|c|c|c|c|}
\hline \multirow[t]{2}{*}{ Onset of infection } & \multicolumn{3}{|c|}{ Types of disability } \\
\hline & $\begin{array}{c}\text { Ocular } \\
n=33(\%)\end{array}$ & $\begin{array}{c}\text { Hearing } \\
\mathrm{n}=32(\%)\end{array}$ & $\begin{array}{c}\text { Cardiac } \\
\mathrm{n}=31(\%)\end{array}$ \\
\hline 1st trimester & $28(85)$ & $29(91)$ & $29(94)$ \\
\hline 2nd trimester & $3(9)$ & $1(3)$ & $0(0)$ \\
\hline 3rd trimester & - & - & - \\
\hline Unknown & $2(6)$ & $2(6)$ & $2(6)$ \\
\hline
\end{tabular}

Among systemic complications of CRS, neurological problem was found in 36(90\%) cases. This is followed by visual problems in 33(83\%) cases, congenital hearing loss in $32(80 \%)$ cases and cardiac defects in 31(78\%) cases. Organomegly and neonatal jaundice were associated complications (Fig 2).

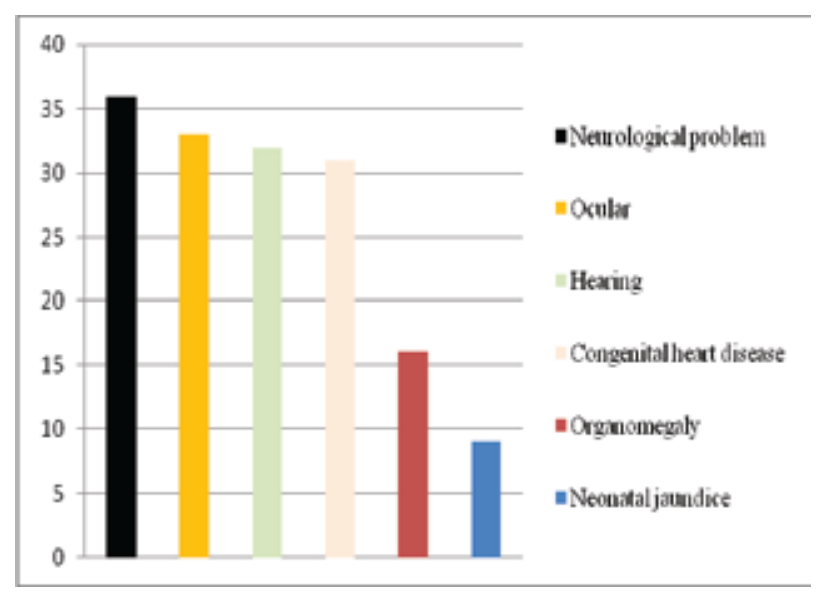

Fig 2: Systemic manifestations of CRS patients

Among ocular manifestations cataract was found in $22(55 \%)$ cases followed by chorioretinitis in $12(30 \%)$ cases, micropthalmia in $8(20 \%)$ cases, glaucoma in $6(15 \%)$ cases, strabismus in $6(15 \%)$ cases, and nystigmus in 3(8\%) cases (Fig 3).

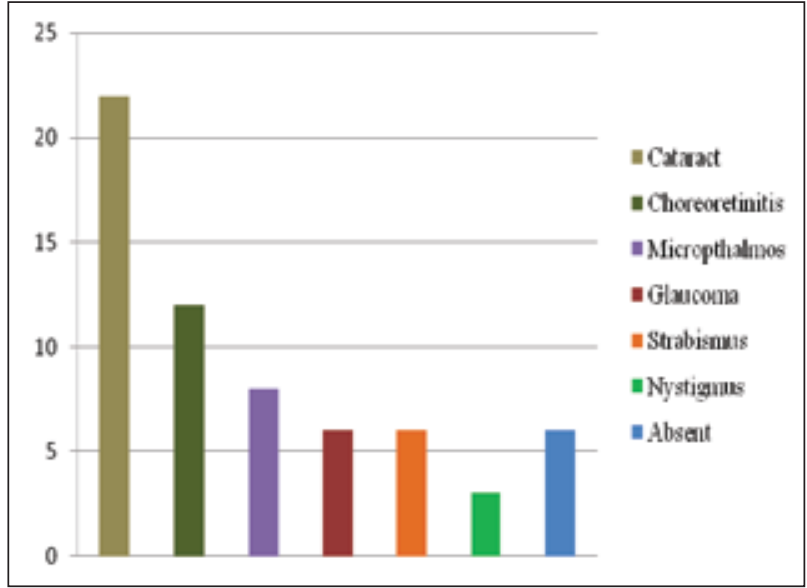

Fig 3: Ocular manifestations of CRS

Among neurological manifestations, microcephaly was reported in $25(62 \%)$ patients, followed by other manifestations including motor delay in $14(35 \%)$, cerebral palsy in $12(30 \%)$, epilepsy in $9(23 \%)$, hydrocephalous in $5(12 \%)$ and intracranial calcification in 3(7\%) cases (Fig 4).

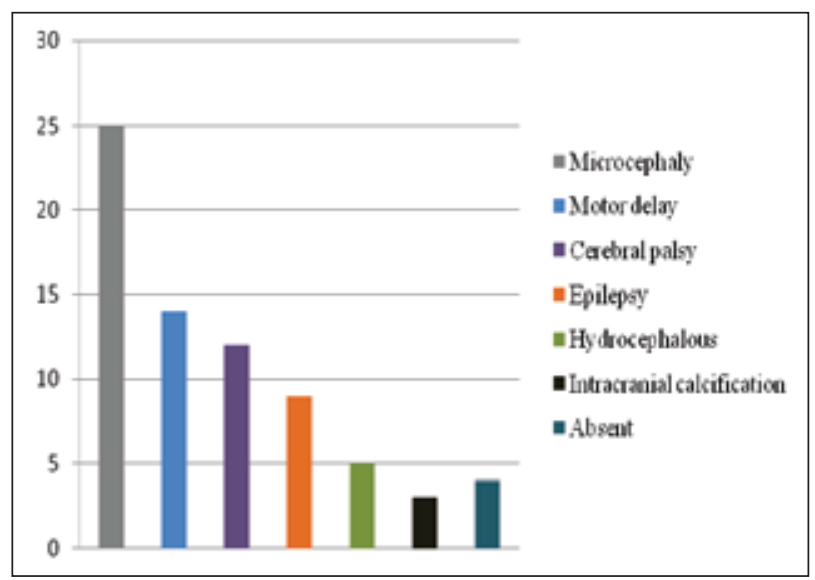

Fig 4: Neurological manifestations of CRS

Echocardiography findings revealed isolated patent ductus arteriosus (PDA) in 15(38\%) cases, pulmonary stenosis (PS) in $4(10 \%)$ cases, atrial septal defect (ASD) in 2(5\%) cases and tetralogy of Fallot (TOF) in 3(8\%) cases. Combined defects were PDA with ASD in 2(5\%) cases, PDA with ventricular septal defect (VSD) in $1(3 \%)$ case, PDA with ASD and TOF in $1(3 \%)$ case and PS with ASD in $1(3 \%)$ case. VSD was associated with ASD in $1(3 \%)$ case and with truncus arteriosus in 1(3\%) case. Cardiac disorder was absent in 9(23\%) cases (Fig 5). 


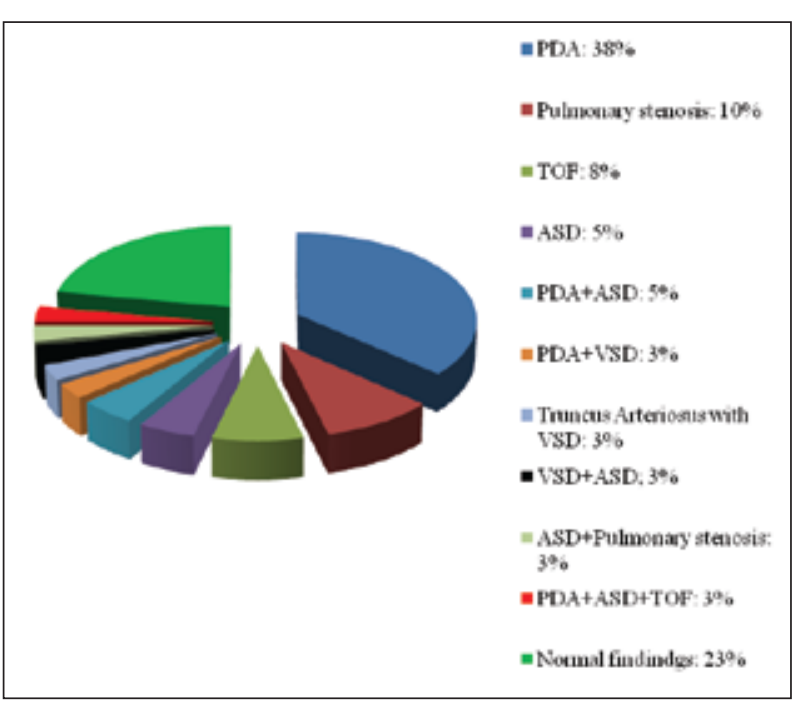

Fig 5: Pattern of CHD according to echocardiography finding $(n=40)$

\section{Discussion}

This study was done to evaluate the clinical manifestations of Congenital Rubella Syndrome (CRS) in children admitted to tertiary level hospitals of Bangladesh. During study period, a total of 40 children were diagnosed as CRS on the basis of standard case definition. ${ }^{11}$

In this study $\operatorname{IgG}$ was positive in $60 \%$ patients as documented by ten fold rise than upper limit of normal value and $28 \%$ patients revealed positive IgM. Although WHO and Centre for Disease Control (CDC) recommended confirmation of CRS by detection of rubella specific IgM in blood and persistence of rubella IgG titres over time, i.e., no decline in titre as expected for transplacentally derived maternal $\operatorname{IgG}$ (by 6 months), ${ }^{13} \mathrm{IgM}$ is more specific serological test than $\operatorname{IgG}$ and confirmation of the diagnosis based solely on the presence of rubella IgG is difficult. ${ }^{14}$ Rubella specific IgM can be detected in almost $100 \%$ of infected infants of 0-3 months of age. However, the percentage of IgM positive infants progressively declines over the first year of life (less than $50 \%$ ), by 1 year most infants are negative. But IgM may not be detected until at least 1 month of age. 15 This could be due to high rubella specific IgG titers of both self and maternal origin that tend to compete with IgM antibodies for binding. 15 In this study, all the IgM positive children were within 0-3 months of age.
In an Indian study, 26\% children were seropositive for rubella $\operatorname{IgM}$ which is consistent with this study $(28 \%) .16$ Therefore, being more specific for confirmation, serum IgM estimation alone may under-diagnose CRS compared to combination of both the tests (IgM and $\operatorname{IgG})^{16}$ and rubella-specific IgG test is more practical for diagnosing CRS in children aged $>6$ months. ${ }^{17}$ Recently, PCR has been developed as more sensitive than virus isolation for the detection of rubella RNA. However, in developing countries, neither may be practical.16 For many reasons, including laboratory capabilities and cost issues, $\operatorname{IgM}$ and $\operatorname{IgG}$ testing for rubella infection are more likely to be available in developing countries like ours. ${ }^{17}$ In 3 children serum was difficult to obtain due to parental refusal and serological result was equivocal for IgG in two patients. They could be potential cases of laboratory confirmed CRS.

Among total 40 CRS patients (0 to 24 months of age), majority was from $0-6$ months age group $(53 \%)$. The mean $( \pm \mathrm{SD})$ age was $6.6( \pm 5.7)$ months and male female ratio was $2: 1$. It was unclear why male child was predominant in CRS cases, but in many studies the male female ratio were almost the same. 14,15 In this study, most patients $(62 \%)$ with CRS came from poor socioeconomic status which is consistent with a study done abroad. 18 In a study on Bangladeshi children, higher prevalence of rubella antibody was observed in lower socioeconomic class. 19

The risks of developing congenital defects in CRS are inversely related to gestational age. The risk is up to $90 \%$ if infection occurs during the first 11 weeks of gestation and decreases with infection after 12 weeks of gestation and after 16 weeks the incidence of foetal damage is less than $2 \% .{ }^{15,19} \mathrm{We}$ also found that onset of infection was highest in first trimester of pregnancy.

The pattern of the systemic manifestations in CRS varied in different studies. Most authors documented ocular problem as the predominant manifestation of CRS, whereas hearing defect was the commonest in other studies. Neurological problems were the next common CRS manifestation followed by congenital heart disease.20,21 In our study, neurological problem was found in largest number $(90 \%)$ of children, probably due to getting many patients from Child Development Centre. 
It was followed by, visual problems (83\%), congenital hearing loss $(80 \%)$ and cardiac defects (78\%) that goes with most of the studies.

Cataract was the most commonly reported ocular manifestation in several studies, which is consistent with this study.20 Other common visual problems are chorioretinitis, micropthalmos and congenital glaucoma as in this study. 22 Among neurological manifestations, microcephaly was highest in number (62\%) followed by other manifestations like motor delay (35\%), cerebral palsy (30\%), epilepsy (22\%), hydrocephalous (12\%) and intracranial calcification (7\%). This distribution was almost same as in other international studies. ${ }^{14}$

Regarding pattern of cardiac problems, PDA was reported as the predominant CHD by several authors, followed by PS.23,24 It is consistent with this study. Pulmonary stenosis and septal defect were also commonly associated with PDA in different studies. ${ }^{21}$ In this study, isolated PDA was found in most (37.5\%) children and PS was found in $10 \%$ cases. However, a wide variety of cardiac problems, associated with CRS was found in this study like ASD, VSD, TOF and truncus arteriosus like other international studies. 25

Rubella is a major public health problem and CRS presents with a diverse form of clinical patterns which increases childhood morbidity and mortality. Multiple modalities of management are required for each clinical entity. The paediatricians should be aware of early detection of clinical problems in relation with CRS.

In this study, many patients had more than one congenital defect. So, physicians should be aware of searching different disabilities in a child with suspected CRS and refer to respective specialty for better management and outcome.

\section{Limitation of the study}

A limitation of this study was the relatively small sample size and that data were collected from only two selected institutions. In this study, only a single serum sample was taken from each child; serial specimens demonstrating a sustained titre of $\operatorname{IgG}$ would provide further confirmation of CRS and infants who tested negative IgM shortly after birth could be retested later.

\section{References}

1. Gershon A. Rubella (German measles). In: Fauci A, editor. Harrison's Principles of Internal Medicine. 14th ed. New York: McGraw-Hill; 2001.p.1125-27.

2. Atreya CD, Mohan KV, Kulkarni S. Rubella Virus and Birth Defects: Molecular Insights into the Viral Teratogenesis at the Cellular Level. A Clin Mol Teratol. 2004;70(7):431-37.

3. Rubella Vaccines: WHO Position PaperRecommendations. Vaccine. 2011; 29(48):8767-68.

4. Rubella Vaccines: WHO Position Paper. Wkly Epidemiol Rec. 2000;75:161-69.

5. Sadighi J, Eftekhar H, Mohammad K. Congenital Rubella Syndrome in Iran. BMC Infectious Diseases [Internet]. 2005 [cited 2013 Mar 12];5(44). Available from: http://www.bio medcentral. com/14712334/5/44.

6. Diorditsa S. Progress and Challenges in Bangladesh. WHO Global Measles and Rubella Management Meeting [Internet]; 2011 March 15-17; WHO HQ, Geneva. [cited 2013 Dec 10]. Available from: http://www.measlesrubellainitiative.org/wpcontent/uploads.

7. Imam H, Yasmin M, Ahsan CR, Nessa J. Pregnant Women in and around Dhaka City: are Their Children at Risk of Developing Congenital Rubella Syndrome? Indian Journal of Microbiology. 2010;50(4):443-48.

8. Cooper LS. The History and Medical Consequences of Rubella. Rev Infect Dis. 1985;7:52.

9. Pelletier L, Duclos P. Surveillance of Congenital Rubella Syndrome and Other Rubella-Associated Adverse Pregnancy Outcomes. Can Commun Dis Rep. 1996;22(5):35-37.

10. van Dijk J, Swets S, Zeitlinger BV. Rubella Handicapped Children. The Netherlands. 1982;68:15-16.

11. Progress toward Control of Rubella and Prevention of Congenital Rubella Syndrome - Worldwide, 2009, Centers for Disease Control and Prevention (CDC). MMWR Morb Mortal Wkly Rep. 2010;59:1307-10.

12. UNICEF. State of the Children of the World, 2007 [Internet]. 2007 [cited 2013 Mar 12]. Available from: http://www.unicef.org/publications/files/The_State_ of_the_Worlds_Children_2007_e.pdf.

13. Banatvala JE, Bron DW. Congenital Rubella Syndrome as a Systemic Infection. Studies of Affected Infants Born in Philadelphia, U.S.A. Lancet. 2004;363:1127-37. 
14. Hussain N, Jaffery G, Hasnain S, Anwar K. Seroprevalence of Rubella IgG and IgM Antibodies in Infants Suspected of Having Rubella Infection. Biomedica. 2006;22:25-30.

15. Canep P, Valle L, Critina E, Florenti D, Parodi V, Banfi F, et al. Role of Congenital Rubella Reference Laboratory: 21-Months-Surveillance in Liguria, Italy. J Prev Med Hyg. 2009;50:221-26.

16. Rajaundri TA, Sundaresan P, Vijayalakshmi P, Brown DW, Jin L. Laboratory Confirmation of Congenital Rubella Syndrome in Infants: An Eye Hospital Based Investigation. J Med Virol. 2008;80:536-46.

17. Kyaw ZT, Win MO, Thein TM, Than NS, Aye MH, Khin MA, et al. Active Surveillance for Congenital Rubella Syndrome in Yangon, Myanmar. Bull World Health Organ. 2006;84:12-20.

18. Cyrus A, Lotfi M. Association of Socioeconomic Status and Fetal Congenital Abnormalities. American Journal of Scientific Research. 2012;58:148-54.

Jubaida N, Mondal M, Kawsar NM. Seroprevalence

19. of Rubella Antibodies in Pregnant Women. JAFMC Bangladesh. 2011;7(1):88-94.
20. Khandekar R, Awaidy S A, Ganesh A, Bawikar S. An Epidemiological and Clinical Study of Ocular Manifestations of Congenital Rubella Syndrome in Omani Children. Arch Ophthalmol. 2004;122:541-45.

Rahman MM, Khan AM, Hafiz MM, Ronny FMH,

21. Ara S, Chowdhury SK, et al. Congenital Hearing Impairment Associated with Rubella: Lessons from Bangladesh. Southeast Asian J Trop Med Public Health. 2002;33(4):811-17.

Vijayalakshmi P, Kakkar G, Samprathi A. Ocular

22. Manifestations of Congenital Rubella Syndrome in a Developing Country. Indian J Ophthalmol. 2002;50:307-11.

Sateesh K, Bhandary M, Shwetha S, Vadisha SB,

23. Biniyam K, Vijaya S. Case Report Congenital Rubella Syndrome: It Still Exists in India. Journal of Clinical and Diagnostic Research. 2012;6(2):301-302.

Zimmerman L, Reef SE. Incidence of Congenital

24. Rubella Syndrome at a Hospital Serving a Predominantly Hispanic Population, El Paso, Texas. Pediatrics. 2001;107(e40):1-4.

Dewan P, Gupta P. Burden of Congenital Rubella 25. Syndrome (CRS) in India: A Systematic Review. Indian Pediatr. 2012;49:377-99. 